\title{
The management of technology and women in two electronics firms in Malaysia
}

\begin{abstract}
Today, given the state of Malaysia's industrialization, the issue of cultural and social stigmatization of women workers is no longer relevant. The empirical picture shows that with increasing automation, there has been more emphasis and concern about appropriate human resource management strategies that have been used upon labor. This study indicates that in the capital-intensive electronics industry, management has been successful in eliciting consent from their workers to cooperate and to be in step with every new technology introduced. This article looks at the evidence of changing technology at the workplace, and documents management strategies that are currently being employed to control, contain, empower or enhance labor. By doing so, we assess the current impact upon women workers brought about by the adoption of new technologies and contemporary human resource management tools, all of which are issues that labor unions and feminists might wish to be aware of in order to set new agendas for the movement. This article will briefly discuss the background of Malaysia's industrialization policy, in which the electronics industry is a key player. This will be followed by a short discussion on women's economic position in Malaysia to provide the backdrop to the situation of electronics workers in the context of globalization and changing technology. The relationship between current human resource management practices and new technology, and women workers' responses to these changes, will be taken up in the ensuing sections.
\end{abstract}

Keyword: Technology; Women; Malaysia 